127 control catheters. These showed no significant differences in encrustation of the tips and balloons (eight conformable, nine control catheters; $\chi_{1}^{2}=0.01, p>0.900$ ). The difference in blockage at the lower ends (one conformable, six control catheters), however, just failed to reach significance $\left(\chi_{1}^{2}=3.62 ; p=0.057\right)$

\section{Discussion}

This work supports the claim that the conformable catheter causes less trauma, is more comfortable, and is less likely to obstruct at the central and distal portions (though not at the tip). Statistical analysis of the 12 week trial showed that though the conformable catheter was more comfortable overall, comfort was related in part to the order in which the catheters were used. Patients found the control catheter less comfortable when it was inserted after they had used the conformable catheter.

Episodes of bypassing were fewer with the conformable catheter but not significantly so. The rejection (extrusion) rates in study B were $17 \cdot 8 \%$ and $32 \cdot 7 \%$ for the conformable and control catheters as compared with $45 \%$ in a study of similar long stay geriatric patients. ${ }^{9}$

The evidence in favour of less trauma to the urethra and less obstruction to the lumen of the catheter is objective and includes both histological findings in sheep urethras and naked eye appearances of catheter lumens. The conformable catheter apparently obstructs less in both its urethral and more distal parts, but the flexibility does not diminish encrustation of the intravesical portion.
Diminished encrustation probably explains why the conformable catheters remained longer in situ.

This new catheter marks an improvement on the present Foley catheter, especially in terms of comfort and trauma to the urethra. It is suitable for all forms of catheter drainage in women (other than urethral stricture). A form of the catheter for men is being developed.

We are grateful to Bard Ltd and particularly to Dr T M Sutton and Mrs Christine Seth for their participation and support during this work; to $\mathrm{Mr}$ Brian Faragher for statistical advice; and to the Foundation for Age Research for generous financial support of DSH, ID, and APK.

\section{References \\ 1 Zorgniotti AW. Frederick E B Foley—early development of balloon catheter. Urology 1973; $75-80$. \\ Roberts GR. Dependent drainage balloon catheter. BrMed 7 1969;i:705. \\ Brocklehurst JC, Brocklehurst S. Management of indwelling catheters. Br f Urol 1978;50:102-5. 4 Gibbon N. Some recent developments in bladder drainage. $\mathcal{F} R$ Coll Surg Edinb 1961;6:215-22. Pullen BR, Phillips JI, Hickey DS. Urethral lumen cross-sectional shape: its radiological determination and relationship to function. Br $\mathcal{A}$ Urol 1982;54:399-407. \\ 6 Aitken MA. The analysis of unbalanced cross-classifications (with discussion). Journal of the Royal Statistical Society [A] 1978; 141:195-223. \\ Aitken MA. A simultaneous test procedure for contingency table models. Applied Statistics 1979;28:233-42 \\ 8 Baker RJ, Nelder JA. The GLIM system manual. Release 3. Oxford: Numerical Algorithms Group, 1978. \\ 9 Belfield PW, Young JE, Mulley GP. Rejection of catheters. Br Med f 1985;291:108-9. \\ (Accepted 14 March 1988)}

\title{
White cell accumulation in dependent legs of patients with venous hypertension: a possible mechanism for trophic changes in the skin
}

\author{
P R S THOMAS, G B NASH， J A DORMANDY
}

\begin{abstract}
The mechanism by which chronic venous insufficiency and venous hypertension are associated with ulceration of the legs is not yet understood. To investigate this mechanism further accumulation of white cells in the dependent legs of normal volunteers, patients awaiting surgery for simple varicose veins, and patients with chronic venous insufficiency was studied. About $\mathbf{2 4 \%}$ fewer white cells than in normal subjects left the dependent foot of patients with venous hypertension, and this trapping of white cells, was reversed when the foot was raised; similar changes were not observed in normal subjects or patients with varicose veins.
\end{abstract}

The trophic skin changes typically seen in patients with venous hypertension may be aggravated by damage caused by the repeated accumulation of white cells in the microcirculation.

\footnotetext{
Department of Surgery, St James's and St George's Hospitals, London SW12 8HX

P R S THOMAS, FRCS, research registrar

J A DORMANDY, FRCS, consultant surgeon

Department of Haematology, St George's Hospital Medical School, London SW17 0RE

G B NASH, PHD, research fellow

Correspondence to: Mr Dormandy.
}

\section{Introduction}

Chronic venous insufficiency and venous hypertension are associated with a particularly intractable type of ulceration of the legs. The mechanism is uncertain; earlier theories of venous stagnation and arteriovenous shunting have been overtaken by the fibrin cuff hypothesis proposed by Browse et al. ${ }^{1}$ They suggested that high venous pressure during standing or walking is transmitted to the superficial venules in the skin, causing distension of the local capillary bed and widening of endothelial pores. This allows the passive filtration of fibrinogen, which in the presence of decreased fibrinolytic activity polymerises to form a pericapillary fibrin "cuff." This is thought to act as a barrier to the diffusion of oxygen and other important nutrients.

A recent report by Moyses et al suggested that white cells may accumulate in completely immobile dependent feet of normal subjects during prolonged venous stasis. ${ }^{2}$ This suggested the hypothesis that plugging of capillaries by white cells might contribute to the local ischaemia and ulceration seen in patients with venous disease. Our study tested this hypothesis by investigating the accumulation of white cells in normal subjects and in patients with venous insufficiency of varying severity.

\section{Subjects and methods}

We studied three groups of 10 subjects: four men and six women (mean age $37 \cdot 5$ ) who were volunteers without symptoms or signs of venous disease; five men and five women (mean age $48 \cdot 4$ ) who were awaiting surgery for uncomplicated primary varicose veins; and five men and five women (mean age 51.5) who were attending our venous clinic and had a history of 
deep venous thrombosis and the skin changes typical of chronic venous insufficiency. The patients had been examined and classified by Doppler ultrasonography, strain gauge plethysmography, and foot volumetry.

Patients had been asked to remove any support bandaging or stockings on the day before the study and all subjects were asked to fast for two hours before their appointments. All the measurements were carried out in a room in which the temperature was maintained at $18^{\circ} \mathrm{C}$. A Teflon cannula (external diameter $1.0 \mathrm{~mm}$; Venflon, Viggo) was inserted under local anaesthetic $(0.2 \mathrm{ml}$ of $1 \%$ lignocaine) into the lower end of the long saphenous vein just above the medial malleolus. The first millilitre of the blood sample obtained was discarded and the next millilitre taken for analysis. The cannula was flushed with $0.4 \mathrm{ml}$ heparinised saline when not in use. The studies were carried out on a couch that allowed the subjects to sit up with the minimum of effort; the subjects were asked to rest the dependent leg normally while sitting. After the subjects had rested supine for 30 minutes venous samples were taken (time 0 ); the subjects then sat up, and samples were obtained at $15,30,45$, and 60 minutes. The subjects then lay supine again, and further samples were taken at $1,3,5,7,10,12$, and 15 minutes. Samples were taken from each subject's arm at time 0 and after 60 minutes. An automated counter (Coulter S Plus IV) was used to determine the packed cell volume, red cell count, white cell count, and differential white cell count. The differential count in some samples was checked with stained blood films. Comparisons of samples obtained at different times within and among the groups were made with the Wilcoxon signed rank and Wilcoxon rank sum tests, respectively.

\section{Results}

Figures 1 and 2 and table I show the changes in the composition of venous blood from the foot after the subjects had been sitting for 60 minutes compared to the baseline -values established when the subjects were lying supine. Figure 1 shows the increase in packed cell volume, which was much greater in the patients with venous hypertension than in the other groups. Figure 2 shows the change in the ratio of the white cell count to the red cell count. Only a small change was seen in the normal subjects and the patients with varicose veins, but in the patients with venous hypertension there was a $28.6 \%$ mean decrease in the ratio. Thus in the patients with venous insufficiency lowering the leg for an hour caused an increase in the concentration of red cells but a decrease in the relative number of white cells leaving the foot. No change was seen in any of the groups in the composition of the venous blood taken from the arm.

Figure 3 shows the changes in packed cell volume and cell ratio over time. The patients with primary varicose veins did not differ significantly from the

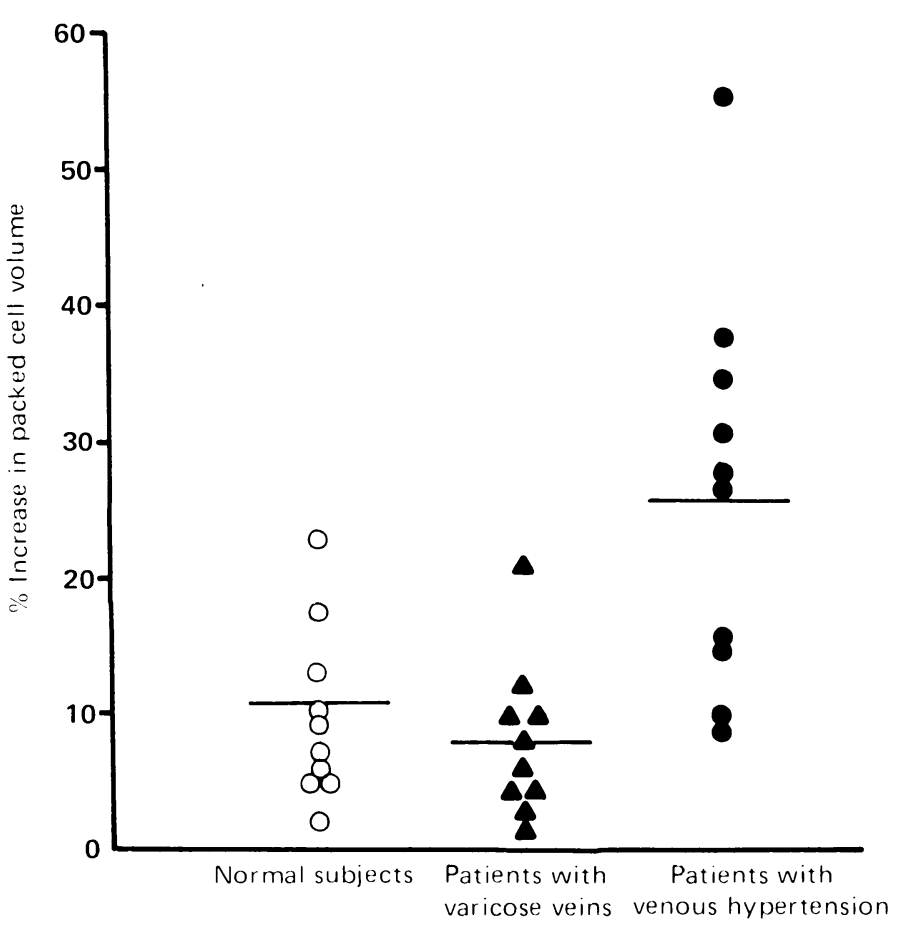

FIG 1-Percentage increase in packed cell volume after 60 minutes' sitting compared with baseline value obtained in supine position. Bars indicate mean values.

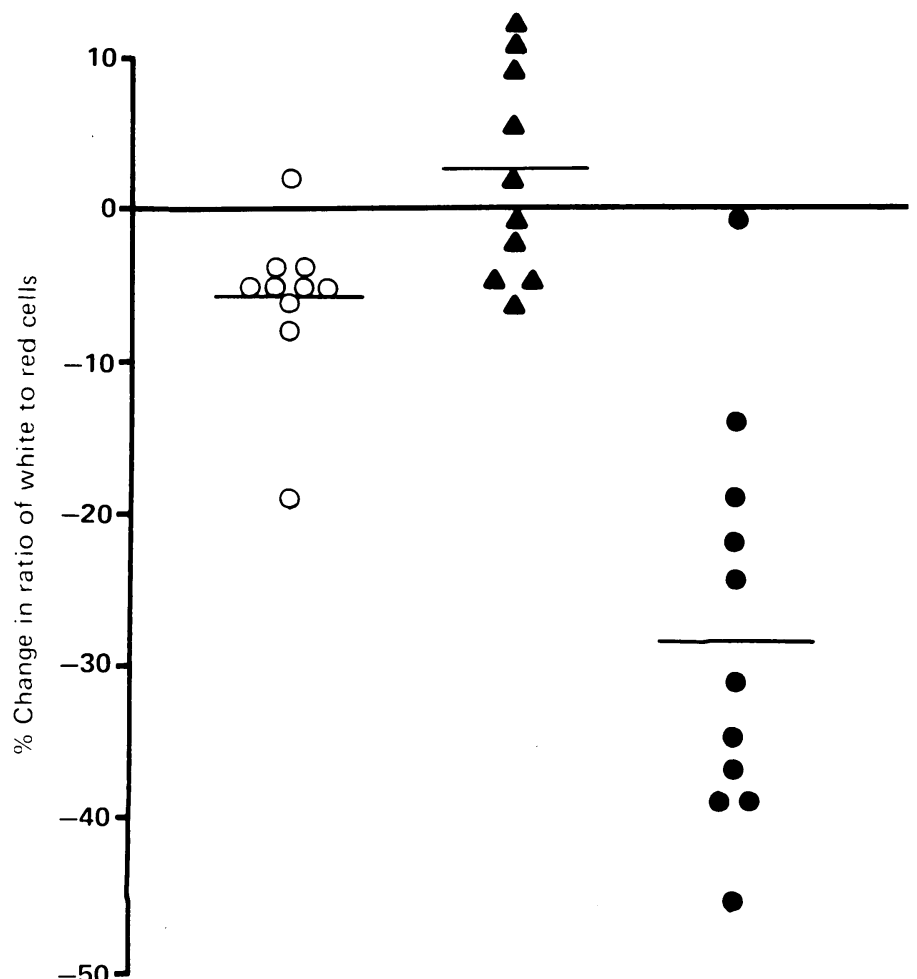

Normal subjects Patients with Patients with varicose veins venous hypertension

FIG 2-Percentage change in ratio of white cells to red cells after 60 minutes sitting compared with baseline value obtained in supine position. Bars indicate mean values.

TABLE I-Composition of venous blood before and after 60 minutes of sitting up with legs dependent. Values are means (SD)

\begin{tabular}{|c|c|c|c|}
\hline & $\begin{array}{l}\text { Normal } \\
\text { subjects } \\
(n=10)\end{array}$ & $\begin{array}{c}\text { Patients } \\
\text { with simple } \\
\text { varicose veins } \\
(n=10)\end{array}$ & $\begin{array}{c}\text { Patients } \\
\text { with venous } \\
\text { hypertension } \\
(\mathrm{n}=10)\end{array}$ \\
\hline \multicolumn{4}{|c|}{ Packed cell volume: } \\
\hline Time $0 \S$ & $0 \cdot 39(0 \cdot 04)$ & $0.42(0.05)$ & $0.39(0.03)$ \\
\hline Time 60 & $0.43(0.05)^{\star \star}$ & $0.46(0.05)^{\star \star}$ & $0.50(0.03)^{\star \star}$ \\
\hline$\%$ Increase & $9 \cdot 6(6 \cdot 0)$ & $7 \cdot 8(6 \cdot 2)$ & $25 \cdot 6(15 \cdot 0) \dagger$ \\
\hline \multicolumn{4}{|c|}{ Ratio of white to red cells $\left(\times 10^{3}\right)$ : } \\
\hline Time $0 \$$ & $1.41(0.34)$ & $1.55(0.53)$ & $1 \cdot 47(0 \cdot 31)$ \\
\hline Time 60 & $1.34(0.36)^{\star \star}$ & $1.57(0.48)$ & $1.05(0 \cdot 19)^{\star \star}$ \\
\hline$\%$ Decrease & $5 \cdot 0(5 \cdot 6)$ & $-1 \cdot 3(8 \cdot 1)$ & $28 \cdot 6(14 \cdot 1) \ddagger$ \\
\hline \multicolumn{4}{|c|}{ Monocytes ( $\%$ of white cells): } \\
\hline Time $0 \$$ & $7 \cdot 5(3 \cdot 4)$ & $7 \cdot 1(2 \cdot 4)$ & $7 \cdot 1(2 \cdot 0)$ \\
\hline Time 60 & $6 \cdot 0(3 \cdot 1)$ & $5 \cdot 7(2 \cdot 7)^{\star}$ & $5.0(1 \cdot 8)^{\star}$ \\
\hline$\%$ Decrease & $19 \cdot 5(25 \cdot 8)$ & $19 \cdot 6(27 \cdot 8)$ & $28 \cdot 3(18 \cdot 9)$ \\
\hline
\end{tabular}

$\$$ After lying down for 30 minutes.

${ }^{\star} \mathrm{p}<0.05,{ }^{\star \star} \mathrm{p}<0.01$ Compared with value at time 0 , Wilcoxon signed rank test. $\mathrm{tp}<0.05, \neq \mathrm{p}<0.01$ Compared with normal subjects, Wilcoxon rank sum test.

normal subjects and are not shown. In the normal subjects the packed cell volume increased during the first 15 minutes after the legs were lowered by about $7 \%$ and subsequently remained fairly constant. By contrast, the patients with venous hypertension showed a progressive increase up to $25 \%$ at 60 minutes. In all three groups the haemoconcentration decreased rapidly when the subjects lay supine again, reaching the baseline value after 10 minutes. The difference in the behaviour of the white cells, as reflected in the ratio of white to red cells, between the normal subjects and the patients with venous insufficiency was significant: the patients with venous insufficiency showed a significantly greater decrease in the relative number of white cells $(28 \% v 5 \%, \mathrm{p}<0.01$; table I). Each group showed a significant rise in the ratio of white to red cells on lying supine ( $p<0.01$; fig 3, table II). The delay in the washout of white cells was measured by the time to peak washout (the time after resumption of a supine position at which the ratio of white cells to red cells was maximum). The difference in this variable between the patients with venous hypertension and the normal subjects was significant $(\mathbf{p}<0.05$; table II).

The differential white cell count at 60 minutes (table I) showed that the 
percentage of monocytes decreased in all groups during sitting. After the subjects lay supine again, however, there was a relative increase in the monocyte count (table II). This clearance of monocytes reached a peak (that is, time to peak washout) at 3.4 minutes in the normal subjects compared with 6.4 minutes in the patients with venous insufficiency $(\mathrm{p}<0.05)$.
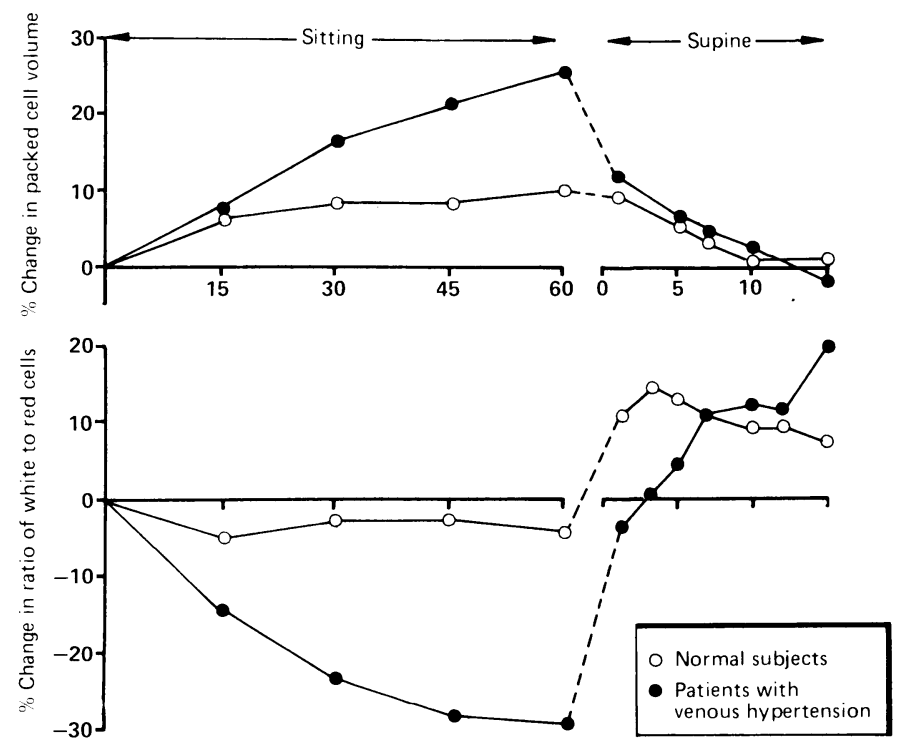

FIG 3-Changes in packed cell volume and ratio of white cells to red cells during 60 minutes of sitting and 15 minutes after resumption of supine position. Changes in patients with varicose veins were similar to those in normal subjects.

TABLE II-Maximum changes in white cell count after patients resumed supine position (washout phase). Values are means (SD)

\begin{tabular}{|c|c|c|c|}
\hline & $\begin{array}{l}\text { Normal } \\
\text { subjects } \\
(\mathrm{n}=10)\end{array}$ & $\begin{array}{c}\text { Patients } \\
\text { with varicose } \\
\text { veins }(n=10)\end{array}$ & $\begin{array}{l}\text { Patients } \\
\text { with venous } \\
\text { hypertension } \\
(\mathrm{n}=10)\end{array}$ \\
\hline \multicolumn{4}{|l|}{ Ratio of white to red cells: } \\
\hline Maximum increase (\%) & $16 \cdot 4(7 \cdot 5)^{\star}$ & $21.8(20 \cdot 6)^{\star}$ & $23 \cdot 3(13 \cdot 2)^{\star}$ \\
\hline Time to peak washout $(\min ) \neq$ & $2 \cdot 5(1.8)$ & $3 \cdot 2(2 \cdot 6)$ & $9 \cdot 2(5 \cdot 6) \dagger$ \\
\hline \multicolumn{4}{|l|}{ Monocytes (as \% of white cells): } \\
\hline Maximum increase $(\%)$ & $21 \cdot 3(34 \cdot 0)^{\star}$ & $11 \cdot 3(21 \cdot 0)^{\star}$ & $12 \cdot 7(31 \cdot 2)^{\star}$ \\
\hline Time to peak washout $(\min ) \ddagger$ & $3.4(1.8)$ & $3.8(1.9)$ & $6 \cdot 4(3 \cdot 2) \dagger$ \\
\hline
\end{tabular}

${ }^{\star} \mathrm{p}<0.01$ Compared with value at time 0 , Wilcoxon signed rank test.

$t p<0.05$ Compared with normal subjects, Wilcoxon rank sum test.

$\neq$ Time from when patients resumed a supine position to when highest ratio of white to red cells or percentage of monocytes was seen.

\section{Discussion}

Moyses et al observed that under certain conditions white cells may accumulate in dependent legs of normal subjects and suggested that this might be due to plugging in the capillaries. ${ }^{2}$ Our normal subjects did not show this accumulation of white cells, probably because they were seated and had not been instructed to remain absolutely still; the patients of Moyses et al remained motionless on an exercise bicycle. Patients with chronic venous insufficiency, however, showed a $28 \cdot 6 \%$ loss of white cells in the microcirculation of the dependent legs.

Venous occlusion plethysmography ${ }^{3}$ and more recently laser doppler flowmetry ${ }^{4}$ have been used to show that cutaneous blood flow decreases when the leg is lowered, probably owing to an increase in precapillary resistance in response to increased arterial and venous hydrostatic pressures. ${ }^{5}$ The physiological importance of this reflex is that by reducing capillary perfusion pressure precapillary vasoconstriction may protect against oedema. Nevertheless, some increase in intracapillary pressure occurs and the resulting loss of fluid through the capillary wall probably explains the increase in packed cell volume we observed in normal subjects and to a greater extent patients with venous insufficiency. Although the intracapillary pressure is greater when standing, the pressure gradient along the capillary is reduced in patients with venous hypertension. This may explain the trapping of white cells, which are roughly 1000 times stiffer than red cells, monocytes being even more resistant than granulocytes. ${ }^{67}$ Our data suggest that at least some of the accumulated white cells are washed out when the normal pressure gradient in the capillaries is restored by raising the foot.

The repeated accumulation of white cells in capillaries and venules of the foot may contribute to trophic changes of the skin and ultimately to ulceration by several mechanisms. Plugging in or slow transit of blood cells through the smaller capillaries may cause uneven flow through the microcirculation. Local ischaemia near a blocked capillary may be sufficient to activate the hypoxic white cells and result in an inflammatory type of response associated with degranulation of the white cells and the release of toxic metabolites of oxygen and proteolytic enzymes. Neutrophil granules contain several constituents capable of mediating vascular injury. Lysozymal proteins increase vascular permeability in vivo, ${ }^{8}$ and acid and neutral proteases may digest vascular basement membrane in vivo and in vitro. ${ }^{9}$ An isolated microenviroment may exist at the interface of a layer of neutrophils and substrate in the capillary wall, allowing proteolytic degradation of components of the endothelial membrane or the subendothelial matrix to occur even in the presence of inhibitors of plasma protease. Another possible mechanism is that high venous pressure during standing or walking may injure the endothelium through the release of agents that activate neutrophils, which may further increase the tendency for white cells to accumulate. ${ }^{10}$

Our findings add to the current hypothesis on the mechanism of venous ulceration (see paper, $p$ 1726) by presenting an alternative mechanism for the increased capillary permeability that precedes the formation of the pericapillary fibrin cuff.

We thank the department of haematology, St George's Hospital, for help with blood counts and Professor C C Michel for helpful discussion.

\section{References}

1 Browse NL, Burnand KG. The cause of venous ulceration. Lancet 1982;ii:243-5

2 Moyses C, Cederholm-Williams SA, Michel CC. Haemoconcentration and accumulation of white Moyses C, Cederholm-Williams SA, Michel CC. Haemoconcentration and acc
cells in the feet during venous stasis. Int $\mathcal{F}$ Microcirc Clin Exp 1987;5:311-20.

3 Gaskell P, Burton AC. Local postural vasomotor reflexes arising from the limb veins. Circ Res 1953;i:27-39.

4 Hassan AAK, Rayman G, Tooke JE. Effect of indirect heating on the postural control of skin blood flow in the human foot. Clin Sci 1986;70:577-82.

5 Levick JR, Michel CC. The effects of position and skin temperature on the capillary pressures in the fingers and toes. I Physiol (Lond) 1978;274:97-109.

6 Chien S, Schmalzer EA, Lee MML, Impelluzo T, Skalak R. Role of white blood cells in filtration of blood cell suspensions. Biorheology 1983;20:11-27.

Nash GB, Dormandy JA, Meiselman HJ. Comparison of the rheological properties of different white blood cell subpopulations. Clinical Haemorheology 1987;7:433.

Janoff A, Schaefer S, Scherer J, Bean MA Mediators of inflammation in leukocyte lysosomes. II Mechanism of action of lysosomal cationic protein upon vascular permeability in the rat. Mechanism of action of ly

9 Cochrane CG, Aiken BS. Polymorphonuclear leukocytes in immunologic reactions. The destruction of vascular basement membrane in vivo and vitro. F Exp Med 1966;124:733-9.

10 Shirley HH, Wolfram CG, Wasserman K, Mayerson HS. Capillary permeability to macromolecules: stretched pore phenomenon. I Physiol 1957;190:1643-6.

(Accepted 26 January 1988

\section{ONE HUNDRED YEARS AGO}

The Englishman's love of his "cold tub" appears to be a standing puzzler to persons not to the manner born. Professor Dujardin-Beaumetz, the eminent Paris physician, in a learned lecture on hydrotherapy, published in the Therapeutic Gazette, makes the following observations, which show that he labours under a slight misapprehension: "Lotions of cold water and sponge baths have passed from the domain of medicine to that of hygiene, and the people of the North practise them constantly, especially the English, who, in their fondness for their bath-tubs, are in the habit every morning of taking a thorough rub down with a sponge dipped in cold water." 